\title{
Tris(2,3-dibromopropyl) Isocyanurate, Hexabromocyclododecanes, and Polybrominated Diphenyl Ethers in Mollusks from Chinese Bohai
} Sea

Nali Zhu, ${ }^{\dagger}$ An Li, ${ }^{\ddagger}$ Thanh Wang, ${ }^{\dagger}$ Pu Wang, ${ }^{\dagger}$ Guangbo Qu, ${ }^{\dagger}$ Ting Ruan, ${ }^{\dagger}$ Jianjie Fu, ${ }^{\dagger}$ Bo Yuan,
Lixi Zeng, ${ }^{\dagger}$ Yawei Wang, ${ }^{*}{ }^{\dagger}$ and Guibin Jiang

${ }^{\dagger}$ State Key Laboratory of Environmental Chemistry and Ecotoxicology, Research Center for Eco-Environmental Sciences, Chinese Academy of Sciences, Beijing 100085, China

${ }^{\ddagger}$ School of Public Health, University of Illinois at Chicago, Chicago, United States

${ }^{\S}$ Graduate University of Chinese Academy of Sciences, Beijing, China

\section{Supporting Information}

ABSTRACT: A novel brominated flame retardant (BFR), tris(2,3-dibromoprop$\mathrm{yl}$ ) isocyanurate (TBC), as well as hexabromocyclododecanes (HBCDs) and polybrominated diphenyl ethers (PBDEs), were analyzed in 11 species of mollusks collected from nine coastal cities around the Chinese Bohai Sea in 2009 and 2010. The detection frequencies were $100 \%, 99 \%$, and $77 \%$ for PBDEs, HBCDs, and TBC, respectively. Concentrations of $\sum$ HBCDs ranged from below detection limit (nd) to $28.8 \mathrm{ng} \mathrm{g}^{-1}$ on a dry weight $(\mathrm{dw})$ basis, followed by $\sum_{12}$ PBDE (0.01-20.4 $\mathrm{ng} \mathrm{g}^{-1} \mathrm{dw}$ ) and TBC (nd-12.1 $\mathrm{ng} \mathrm{g}^{-1} \mathrm{dw}$ ). Statistically significant linear correlations were found among the three BFRs. Positive correlations were found between BFRs concentrations and lipid content in mollusks. The concentrations tend to decrease with increasing trophic levels of the mollusks, implying trophic dilution rather than biomagnifications of the BFRs in the aquatic food chains of the sampling area. Among the 11 mollusks species,

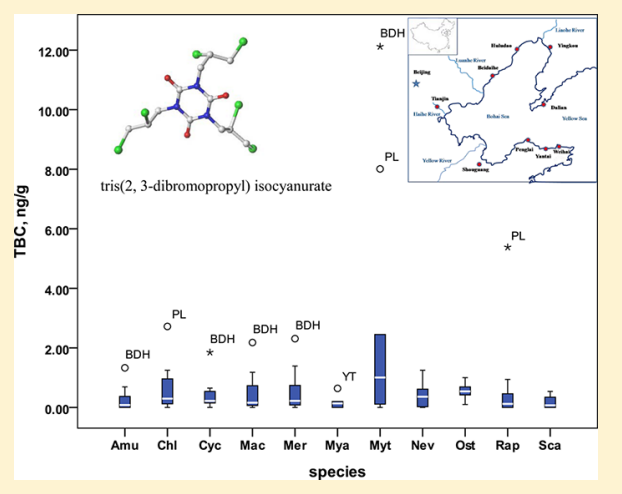
Mytilus edulis showed higher bioaccumulation capability than others and was therefore considered to be an appropriate bioindicator of contamination by the BFRs in the Chinese Bohai Sea, in agreement with its previous selection for the biomonitoring of organochlorine pesticides (OCPs) and polychlorinated biphenyls (PCBs). A dramatic decrease in PBDE concentrations in mollusks of the area was found for the time period from 2003 to 2010 , with a half-life of only $2.3 \pm 1.7$ years, reflecting a rapid response of mollusks to the change in pollution of the marine environment.

\section{INTRODUCTION}

Brominated flame retardants (BFRs) have been widely utilized for the past several decades around the world. In China, the estimated domestic production of BFRs is 81000 tonnes in 2006. ${ }^{1}$ Among the commercial BFRs, polybrominated diphenyl ethers (PBDEs) and hexabromocyclododecanes (HBCDs) and tetrabromobiphenol A (TBBPA) have been manufactured with the highest production volumes both globally and in China. ${ }^{2}$ Due to their adverse effect on the environment and human health, two commercial PBDE products have been included in the list of persistent organic pollutants (POPs) in the Stockholm Convention on POPs, while HBCDs are currently under assessment for possible inclusion. ${ }^{3-6}$ A novel BFR, tris(2,3-dibromopropyl) isocyanurate (TBC), has recently been identified in the environment. ${ }^{7}$ The first reported use of TBC as an additive flame retardant in styrene polymers appeared in $1959,{ }^{8}$ which was followed by a number of patents in Europe and Japan in the 1970s, although information on its large-scale production in these countries has not been found. A technical product containing TBC is Armoquell FR930 manufactured by AkzoNobel Functional Chemicals headquartered in The
Netherlands and operated in many countries. The product is a white to off-white powder specially developed for use in polypropylene, polyethylene, and polystyrene. In China, TBC has been widely applied in polymer products since the mid1980s. ${ }^{9}$ The number of patent applications involving TBC as flame retardant has increased in recent years, mostly from Japan and China. Following the cessation of commercial production of penta- and octa-BDEs worldwide, deca-BDE production has been phased out in Europe and its use in the U.S. will end. Therefore, increasing production and use of TBC may be expected.

Nonetheless, the potential environmental occurrence of TBC has not been given attention until recently. It was recently detected in the water, sediment, and biota samples near a manufacturing factory in southern China ${ }^{7}$ at concentrations as high as $6000 \mathrm{ng} / \mathrm{g}$ dry weight in the sediment. However, there

Received: February 27, 2012

Revised: June 3, 2012

Accepted: June 4, 2012

Published: June 4, 2012 
is no study on the investigation of the environmental occurrence of TBC outside manufacturing source affected areas. With a hexabrominated heterocyclic s-triazine structure (Figure 1), TBC has high thermal stability, durability, and

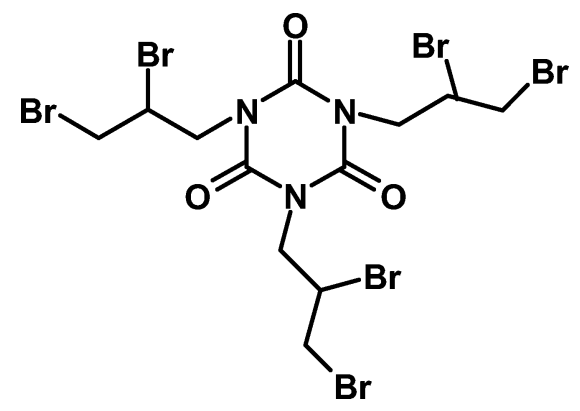

Figure 1. Molecular structure of tris(2,3-dibromopropyl) isocyanurate (TBC).

resistance to photodegradation based on model calculations. ${ }^{7}$ Its high calculated octanol-water partition coefficient $\left(\log K_{\text {ow }}\right.$ $=7.37)$ and bioconcentration factor $(\log \mathrm{BCF}=4.30)$ indicate that TBC is bioaccumulative. ${ }^{10}$ The long-range transport potential of TBC is unknown, but the estimated low vapor pressure $\left(1.57 \times 10^{-13} \mathrm{~Pa}\right)$ and high octanol-air partition coefficient $\left(\log K_{\mathrm{oa}}=23.7\right)$ suggest it is strongly sorptive to surfaces and particles. Recent studies on zebrafish embryos suggested that exposure to TBC causes a variety of potential reproductive and endocrine disrupting toxic effects, damaging mitochondria and causing defects in gas bladder inflation. ${ }^{11,12}$

Mollusks are invertebrate benthic organisms that are present in marine and fresh water with a wide geographical distribution. They have many characteristics that are suitable as bioindicators of POPs contamination. ${ }^{13}$ As water-respiring filter feeders, mollusks have high bioaccumulation potential for POPs due to their relatively high lipid content and low metabolic enzyme activities. Mollusks have good tolerance to a wide spectrum of pollutants which often coexist in polluted water and sediment and are easy to be identified and collected. Mollusks have therefore been commonly used to assess organic pollutant contamination in aquatic systems. ${ }^{14}$

This study was carried out to investigate the levels of TBC, HBCD, and PBDEs in mollusks collected from coastal areas along the Chinese Bohai Sea. The objectives are to study the spatial distribution patterns and compare them among different mollusk species as bioindicator. To our knowledge, this is the first study investigating the environmental occurrence of TBC at locations far away from its manufacturing sites. HBCDs show many characteristics of POPs, ${ }^{15}$ but there is currently no regulation or control on their production or use in China. Compared to PBDEs, research on the environmental occurrence of HBCDs in China is relatively scarce and mostly in source regions such as e-waste recycling areas and industrial areas. ${ }^{16,17}$ No previous examination on HBCD contaminations in mollusks from the study region has been reported. HBCDs are therefore included in this work. The inclusion of PBDEs in this work allowed not only a comparison among the BFRs but also the delineation of temporal trend by combining the data from this work with those of our earlier study. ${ }^{18}$

\section{EXPERIMENTAL SECTION}

Sampling. In August 2009 and 2010, 11 species of mollusks were collected from nine coastal sites (Figure S1, Supporting
Information) near the cities of Dalian (DL), Yingkou (YK), Huludao (HLD), Beidaihe (BDH), Tianjin (TJ), Shouguang (SG), Penglai (PL), Yantai (YT), and Weihai (WH). These sampling locations encompass the near shore areas of four Chinese provinces in the Bohai Bay Rim Economic Zone, which has experienced rapid socioeconomic development in the past decade.

The 11 selected species of mollusks were Neverita didyma (Nev), Rapana venosa (Rap), Mya arenaria (Mya), Cyclina sinensis (Cyc), Chlamys farreri (Chl), Scapharca subcrenata (Sca), Meretix meretrix (Mer), Mytilus edulis (Myt), Crassostrea talienwhanensis (Ost), Amusium veneriformis (Amu), and Mactra veneriformis (Mac). Their denominations are presented in Table S1 (Supporting Information). The mollusks were depurated in filtered water for about $12 \mathrm{~h}$ when sampling, transported to the laboratory on ice, and then cleaned by water in the laboratory. The soft tissue of the mollusks was excised by stainless steel scalpel blades and thoroughly rinsed with Milli-Q water to remove extraneous impurities. For each species from a sampling site, about 500-1500 g of wet soft tissue (consisting of 3-30 individuals) was homogenized in a blender to form one composite sample. The samples were kept at $-20{ }^{\circ} \mathrm{C}$ until analysis. A total of 131 composite soft tissue samples were obtained and analyzed (94 in 2009 and 37 in 2010).

Sample Preparation. The homogenized samples were freeze-dried and sieved. Sample pretreatment was based on our previous methods ${ }^{19,20}$ with modifications. Briefly, $1.5 \mathrm{~g}$ of dried sample was mixed with $15 \mathrm{~g}$ of anhydrous sodium sulfate; spiked with ${ }^{13} \mathrm{C}$-labeled BDEs 47, 99, and 153 and $\gamma$-HBCD (Wellington Laboratories, Guelph, Canada) surrogate standards; and extracted on an accelerated solvent extractor (Dionex ASE350) in a mixture of $1: 1(\mathrm{v}: \mathrm{v})$ dichloromethane:hexane at $150{ }^{\circ} \mathrm{C}$ and $1500 \mathrm{psi}$. About $10 \mathrm{~g}$ of acidic silica (30\%, w/w) was added into the extract to remove lipid. Then, a glass column filled with anhydrous sodium sulfate was used to filter the extract. The concentrated extract was cleaned up by elution with $100 \mathrm{~mL}$ of hexane and $100 \mathrm{~mL}$ of DCM on a glass column (20 cm length and $18 \mathrm{~mm}$ i.d.) packed with, from bottom to top, $1 \mathrm{~g}$ of activated silica gel, $4 \mathrm{~g}$ of basic silica gel $(1.2 \% \mathrm{w} / \mathrm{w})$, $1 \mathrm{~g}$ of activated silica gel, $8 \mathrm{~g}$ of acid silica gel $(30 \%, \mathrm{w} / \mathrm{w}), 2 \mathrm{~g}$ of activated silica gel, and $4 \mathrm{~g}$ of anhydrous sodium sulfate. PBDEs were eluted in the first $100 \mathrm{~mL}$ fraction while HBCDs and $\mathrm{TBC}$ in the second fraction. The two fractions were separately rotary-evaporated and concentrated under a gentle nitrogen flow. Solvents of the first fraction and the second fraction were changed to $20 \mu \mathrm{L}$ of nonane and $100 \mu \mathrm{L}$ of methanol, respectively. Finally, $\left[{ }^{13} \mathrm{C}_{12}\right]$-labeled $2,2^{\prime}, 3,4,4^{\prime}, 5^{\prime}$ hexachlorobiphenyl (CB138, 1668A-IS) and $\left[{ }^{2} \mathrm{H}_{18}\right]$-labeled $\gamma$ HBCD (Wellington Laboratories, Guelph, Canada) were added into the first and the second concentrated fractions, respectively, prior to instrumental analysis.

Instrumental Analysis. Thirteen PBDE congeners including BDEs 17, 28, 47, 66, 71, 85, 99, 100, 138, 153, 154, 183, and 190 were analyzed using a high-resolution gas chromatograph (Agilent 6890) coupled with a high resolution mass spectrometer (Waters Micromass). Three major HBCD diastereoisomers $(\alpha-, \beta$-, $\gamma$-HBCD $)$ and TBC were simultaneously analyzed using a high-performance liquid chromatograph (Waters 2695) equipped with a triple-quadrupole mass spectrometer (Waters Micromass). BDEs 47, 99, and 153 and $\gamma$-HBCD were quantified by isotope dilution methods, while other target analytes were quantified by the internal standard 
Table 1. Concentrations of PBDEs, HBCD, and TBC in Mollusks from Chinese Bohai Sea ${ }^{a}$

\begin{tabular}{|c|c|c|c|c|c|c|c|c|c|c|c|c|}
\hline & $\mathrm{Amu}$ & $\mathrm{Chl}$ & Сус & Mac & Mer & Mya & Myt & $\mathrm{Nev}$ & Ost & Rap & Sca & All \\
\hline$N$ & 11 & 10 & 11 & 7 & 18 & 6 & 10 & 11 & 11 & 25 & 11 & 131 \\
\hline trophic level & 3.05 & 2.96 & 3.07 & 2.99 & 2.96 & 2.66 & 2.79 & 3.23 & 3.02 & 3.43 & 3.07 & \\
\hline lipid (\%) & 11.1 & 14 & 7.5 & 7.9 & 13.4 & 11.1 & 15.3 & 6.5 & 15.7 & 6.7 & 13.2 & \\
\hline \multicolumn{13}{|c|}{$\mathrm{TBC}(\mathrm{DF}=77 \%)$} \\
\hline \multicolumn{13}{|l|}{$\mathrm{ng} / \mathrm{g} \mathrm{dw}$} \\
\hline mean & 0.27 & 0.66 & 0.42 & 0.65 & 0.49 & 0.19 & 2.64 & 0.41 & 0.54 & 0.46 & 0.19 & 0.60 \\
\hline median & 0.08 & 0.30 & 0.22 & 0.22 & 0.22 & 0.14 & 1.01 & 0.36 & 0.54 & 0.12 & 0.07 & 0.21 \\
\hline $\min$ & nd & nd & nd & nd & nd & nd & nd & nd & 0.10 & nd & nd & nd \\
\hline $\max$ & 1.33 & 2.72 & 1.85 & 2.18 & 2.31 & 0.64 & 12.1 & 1.25 & 1.00 & 5.38 & 0.54 & 12.1 \\
\hline \multicolumn{13}{|l|}{$\mathrm{ng} / \mathrm{g} \mathrm{lw}$} \\
\hline mean & 2.44 & 4.70 & 5.59 & 8.20 & 3.66 & 1.71 & 17.2 & 6.30 & 3.44 & 6.90 & 1.44 & 5.60 \\
\hline median & 1.08 & 2.18 & 3.26 & 2.02 & 1.83 & 1.21 & 6.68 & 5.54 & 3.50 & 1.81 & 0.38 & 2.06 \\
\hline $\min$ & nd & nd & nd & nd & nd & nd & nd & nd & 0.76 & nd & nd & nd \\
\hline $\max$ & 13.6 & 19.4 & 26.7 & 29.9 & 14.6 & 5.77 & 139 & 21.2 & 6.37 & 80.3 & 6.84 & 139 \\
\hline \multicolumn{13}{|c|}{$\sum \mathrm{HBCDs}(\mathrm{DF}=99 \%)$} \\
\hline \multicolumn{13}{|l|}{$\mathrm{ng} / \mathrm{g} \mathrm{dw}$} \\
\hline mean & 3.78 & 6.76 & 2.69 & 11.8 & 3.36 & 8.91 & 12.1 & 3.11 & 9.25 & 3.28 & 5.15 & 5.53 \\
\hline median & 4.36 & 6.99 & 1.99 & 7.48 & 2.14 & 8.63 & 11.74 & 1.67 & 7.96 & 2.61 & 3.24 & 3.62 \\
\hline $\min$ & 0.35 & 1.39 & 0.33 & 3.19 & nd & 2.54 & 3.63 & 0.35 & 1.91 & 0.23 & 0.40 & nd \\
\hline $\max$ & 6.26 & 14.1 & 7.83 & 28.8 & 12.1 & 14.7 & 27.7 & 15.1 & 20.0 & 11.2 & 15.7 & 28.8 \\
\hline \multicolumn{13}{|l|}{$\mathrm{ng} / \mathrm{g} \mathrm{lw}$} \\
\hline mean & 34.2 & 48.2 & 35.8 & 148 & 25.1 & 80.2 & 78.9 & 47.8 & 58.9 & 49.2 & 39.0 & 58.7 \\
\hline median & 31.0 & 47.5 & 26.5 & 64.4 & 15.2 & 75.3 & 78.1 & 27.4 & 58.7 & 39.0 & 19.2 & 39.0 \\
\hline $\min$ & 7.69 & 9.93 & 4.40 & nd & nd & 25.4 & 23.37 & 6.62 & 12.2 & 4.20 & 3.03 & nd \\
\hline $\max$ & 59.2 & 147 & 98.8 & 370 & 103 & 134 & 166 & 151 & 129 & 162 & 119 & 370 \\
\hline \multicolumn{13}{|c|}{$\sum_{12} \mathrm{PBDEs}(\mathrm{DF}=100 \%)$} \\
\hline \multicolumn{13}{|l|}{$\mathrm{ng} / \mathrm{g} \mathrm{dw}$} \\
\hline mean & 0.72 & 2.09 & 0.57 & 1.37 & 0.95 & 1.63 & 5.45 & 0.40 & 1.99 & 0.84 & 0.79 & 1.39 \\
\hline median & 0.55 & 2.22 & 0.35 & 0.62 & 0.48 & 0.86 & 3.56 & 0.29 & 1.44 & 0.50 & 0.67 & 0.76 \\
\hline $\min$ & 0.19 & 0.80 & 0.12 & 0.45 & 0.21 & 0.62 & 0.01 & 0.04 & 0.93 & 0.15 & 0.38 & 0.01 \\
\hline $\max$ & 1.54 & 4.26 & 1.54 & 4.44 & 2.54 & 4.94 & 20.43 & 0.78 & 3.35 & 4.17 & 1.53 & 20.4 \\
\hline \multicolumn{13}{|l|}{$\mathrm{ng} / \mathrm{g} \mathrm{lw}$} \\
\hline mean & 6.52 & 14.9 & 7.59 & 17.3 & 7.11 & 14.7 & 35.6 & 6.14 & 12.7 & 12.6 & 5.98 & 12.8 \\
\hline median & 5.61 & 14.5 & 4.67 & 8.50 & 3.92 & 7.78 & 26.2 & 4.46 & 10.1 & 7.46 & 4.30 & 7.56 \\
\hline $\min$ & 1.71 & 5.71 & 1.60 & 5.70 & 1.57 & 5.27 & 0.07 & 0.62 & 5.92 & 3.88 & 2.88 & 0.07 \\
\hline $\max$ & 11.1 & 30.7 & 25.2 & 57.1 & 21.6 & 49.4 & 129 & 16.1 & 21.1 & 91.7 & 14.7 & 129 \\
\hline
\end{tabular}

${ }^{a} \mathrm{DF}(\%)=$ detection frequency; nd $=$ below the MDL. $\sum_{12} \mathrm{PBDEs}=$ sum of 12 major congeners; $\sum \mathrm{HBCDs}=$ sum of $\alpha$-, $\beta$ - and $\gamma$-HBCD.

method. More detailed descriptions of the instrument operational procedures can be found in our previous papers. ${ }^{19,20}$

Quality Control. One procedural blank of $15 \mathrm{~g}$ of anhydrous sodium sulfate was simultaneously analyzed with each batch of five samples. Results showed that HBCDs and TBC in blanks were below the detection limits, while PBDEs (mostly BDEs 47 and 28) were $<5 \%$ of the total PBDEs of real samples. The data reported in this paper were not corrected on the basis of the levels in the blanks.

Six aliquots of a composite mollusk sample were analyzed in replicates, with three of them unspiked and the other three spiked with $100 \mathrm{ng}$ each of the $\alpha$-HBCD, $\beta$-HBCD, $\gamma$-HBCD, and TBC native standards. The recoveries (average \pm standard deviation, $N=3$ ) were $64.6 \pm 8.0 \%, 74.9 \pm 16.5 \%, 106.1 \pm$ $5.1 \%$, and $84.1 \pm 10.8 \%$ for the spiked $\alpha$-HBCD, $\beta$-HBCD, $\gamma$ $\mathrm{HBCD}$, and TBC, respectively. For all the mollusk samples $(N$ $=131$ ), recoveries of ${ }^{13} \mathrm{C}$-labeled BDEs 47, 99, and 153 were $72.2 \pm 18.8 \%, 42.7 \pm 13.1 \%$, and $46.6 \pm 16.0 \%$, respectively, which are within the range of acceptance criteria of the U.S. EPA Method 1614. The recovery of the ${ }^{13} \mathrm{C}$-labeled $\gamma$-HBCD was $83.1 \pm 20.2 \%$. Mean method detection limits (MDL), calculated as 3 times the signal-to-noise ratio on the total ion chromatograph (TIC) of a low level mollusk sample, were 53 $\mathrm{pg} / \mathrm{g} \mathrm{dw}$ for TBC, $0.5-3.3 \mathrm{pg} / \mathrm{g}$ for PBDEs, and 115, 41, and $42 \mathrm{pg} / \mathrm{g}$ for $\alpha$-, $\beta$-, and $\gamma$-HBCDs, respectively.

Mollusks Characterization. The trophic levels of the collected mollusks were determined using stable isotopes ${ }^{15} \mathrm{~N}$, which were analyzed using a flash EA 1112 elemental analyzer interfaced with a Thermo-Finnigan Deltaplus isotope ratio mass spectrometer. The water content was measured by weight loss after drying.

\section{RESULTS AND DISCUSSION}

The mean trophic levels and lipid contents of the mollusks are presented in Table 1 . The water contents of mollusks ranged from $75.9 \%$ to $88.5 \%$, with a mean of $83.3 \%$. Table 1 summarizes the dry weight $(\mathrm{dw})$ based and lipid weight $(\mathrm{lw})$ normalized concentrations of TBC, $\sum_{12}$ PBDEs, and $\sum$ HBCDs in soft tissue of different mollusk species. Concentrations of the individual $\mathrm{HBCD}$ diastereoisomers and PBDE congeners are summarized in Table S2 of the Supporting Information. Among the 131 composite samples analyzed in this study, the detection frequency of $\sum_{12}$ PBDEs was $100 \%$, followed by $\sum$ HBCDs (99.2\%) and TBC (76.9\%). These high detection frequencies 

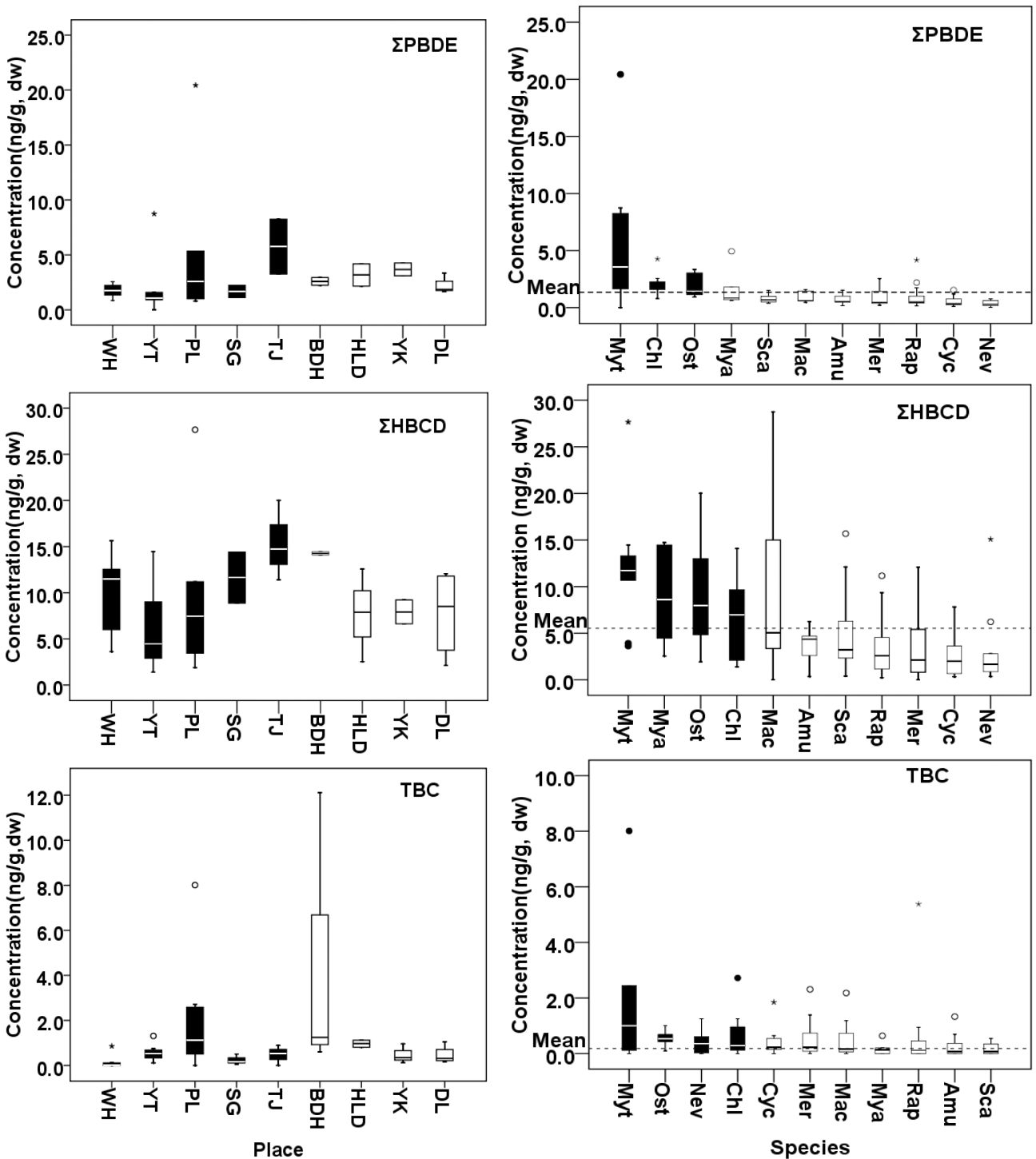

Figure 2. Spatial and species distributions of $\sum_{12}$ PBDEs, $\sum$ HBCDs, and TBC in mollusks. In the left panels, the black boxes represent southern sampling sites, and the white ones represent northern sampling sites. In the right panels, the black boxes represent the mollusk species in which the target compound's concentration is higher than the mean values in all samples. Single values beyond the 150th percentiles of the difference between 25 th and 75th percentiles are presented by "O" or "O", while extreme values are presented by “*”, which are beyond the triplication of the difference between the 25 th and 75 th percentiles.

indicated the ubiquitous contamination in the coastal Bohai Sea by the BFRs. Comparisons among sampling locations and among species are illustrated in Figures 2 and S2 (Supporting Information).

TBC. TBC concentrations ranged from under MDL to 12.1 $\mathrm{ng} / \mathrm{g} \mathrm{dw}$, with means of $0.60 \mathrm{ng} / \mathrm{g} \mathrm{dw}$ and $6.14 \mathrm{ng} / \mathrm{g} \mathrm{lw}$. This concentration range is understandably lower by at least 1 order of magnitude than those found in biota (earthworms and fish) near a TBC manufacturing plant. ${ }^{7}$ The results of this work on mollusks, in combination with previous findings with earthworm and fish, ${ }^{7}$ further indicate that TBC is bioaccumulative. Because many mollusks species are collected for human consumption, it is interesting to find that, in the mollusks species in which TBC was detected, its concentration was comparable to that of $\sum_{12}$ PBDEs (Table 1). The $\log K_{\mathrm{ow}}$ and $\log$ BCF of TBC, obtained using the Estimation Programs Interface (EPI) Suite v4.10 by the U.S. EPA, ${ }^{21}$ are comparable to the estimates for penta-BDE congeners, suggesting similar tendency of bioaccumulation. Noteworthy are the dramatic differences in estimated vapor pressure and air-water distribution ratio $\left(K_{\mathrm{aw}}\right)$ between the two kinds of BFRs. With a vapor pressure of only $10^{-15} \mathrm{mmHg}$ and an extremely low log $K_{\mathrm{aw}}$ of only $16, \mathrm{TBC}$ would preferentially stay in water rather than evaporating into air, in contrast to penta-BDE, which may partition substantially to the atmosphere (vapor pressure $=10^{-6}$ $\mathrm{mmHg}$ and $\left.\log K_{\mathrm{aw}}=-4\right)$.

Relatively weak but statistically significant positive correlations were found between TBC concentrations and $\sum_{12}$ PBDEs $(R=0.24, p=0.015)$ and $\sum$ HBCDs $(R=0.20, p=0.043)$ (Figure S3, Supporting Information), suggesting that the mollusks in this region were exposed to similar sources of the BFRs. In the left panels of Figure 2, the sampling locations are divided into southern sites and northern sites of the Bohai Sea. Most of the southern sampling sites are in Shandong province, where many BFR manufactures and industrial users are located. However, the average TBC concentration is higher in the north $(0.81 \mathrm{ng} / \mathrm{g} \mathrm{dw})$ than in the south $(0.50 \mathrm{ng} / \mathrm{g} \mathrm{dw})$. The highest concentrations of TBC were observed at northern site $\mathrm{BDH}$, a 
summer resort known for its beaches (Figures 2 and S2, Supporting Information). Although unknown, the presence of point sources of TBC in this area cannot be excluded.

HBCDs. $\sum$ HBCDs in mollusks ranged from under MDL to $28.8 \mathrm{ng} / \mathrm{g} \mathrm{dw}$, with means of $5.53 \mathrm{ng} / \mathrm{g} \mathrm{dw}$ and $50.6 \mathrm{ng} / \mathrm{g} \mathrm{lw}$. The concentrations of $\sum$ HBCDs in mollusks were several times higher than those of TBC and $\sum_{12}$ PBDEs. The HBCD concentrations found in this study were comparable to mollusks in Japan ${ }^{5}$ and $\mathrm{UK}^{22}$ but about 10-100 times higher than those in Korea. ${ }^{23}$ A significant linear relationship was found between concentrations of total HBCDs and $\sum_{12}$ PBDEs $(R=0.62, p<0.001)$ in mollusks, as shown in Figure S2 (Supporting Information). Similar findings were observed in fish collected from Yangtze River ${ }^{24}$ and blubber samples of Indo-Pacific dolphins and finless porpoises from Hong Kong in China. ${ }^{25}$ Among the sampling locations of this work, relatively high levels of HBCDs were observed at sites TJ, BDH, and SG. $\mathrm{TJ}$ is the largest industrial city in the Bohai Bay Rim economic zone. SG, within Weifang Prefecture of Shangdong Province, is home to several known BFR manufacturing facilities whose products include technical HBCD.

The technical HBCD is a mixture of several diastereomers, among which $\alpha$-, $\beta$ - and $\gamma$-HBCDs are the major pairs. The mean percentage contribution of $\alpha$-HBCD to the $\sum$ HBCDs in the mollusks of this work was $85.1 \%$, followed by $\gamma$-HBCD (12\%) and $\beta$-HBCD (2.9\%). This finding is consistent with those from other studies on aquatic organisms where $\alpha$-HBCD was the most predominant and is opposite to the commercial mixtures where $\gamma$-HBCD contributes about $80 \%$ to the total HBCDs. ${ }^{26}$ The reasons of aquatic organisms having higher ratio of $\alpha$-HBCD still remain unclear. Some of the possible explanations are that $\alpha$-HBCD has higher bioaccumulative potential or tends to be more resistant to biotransformation ${ }^{5}$ and that $\beta$ - and $\gamma$-HBCD can be isomerized to $\alpha$-HBCD in biota.

PBDEs. The concentration of BDE190 was below the detection limit in all samples and was thus excluded from the data analysis. The concentration of $\sum_{12} \mathrm{PBDE}$ ranged from 0.01 to $20.4 \mathrm{ng} / \mathrm{g} \mathrm{dw}$ with a mean of $1.39 \mathrm{ng} / \mathrm{g} \mathrm{dw}$. The corresponding lipid weight based mean was $12.4 \mathrm{ng} / \mathrm{g}$ lw. The concentrations in Ost and Myt found in this work were 10-100 times lower than those in North America (9-64 ng/g, $\mathrm{dw}){ }^{27}$ Korea (0.38-9.19 ng/g, wet weight), ${ }^{28}$ Hong Kong $(27.0-83.7 \mathrm{ng} / \mathrm{g}, \mathrm{dw}),{ }^{29}$ and Singapore $(2.0-38 \mathrm{ng} / \mathrm{g}, \mathrm{dw}){ }^{30}$ but comparable to those other Asian countries, such as India, Vietnam, Indonesia. ${ }^{5,23}$

The relative abundances of the 12 PBDE congeners were very similar among the 11 mollusks species, with dominant congeners of BDEs 47, 71, 28, and 154, which accounted for $31.4 \pm 7.9 \%, 15.8 \pm 5.3 \%, 15.3 \pm 11.6 \%$, and $11.2 \pm 9.7 \%$ of $\sum_{12} \mathrm{PBDE}$, respectively. BDEs 71 and 28 showed higher proportions than BDEs 99 and 100 in most samples of this study, which is consistent with the findings from two other studies in this area ${ }^{18,31}$ and suggests the possibility of naturally environmental debromination.

Spatial distribution of PBDEs is shown in Figures 2 and S2 (Supporting Information). No significant differences in average $\sum_{12}$ PBDE as well as $\sum$ HBCD were found between southern and northern sampling sites. This observation may suggest that, although manufacturing facilities are dominant sources of the BFRs to the vicinal environment, ${ }^{32}$ their overall impact to the regional aquatic environment might be limited. Among the nine sampling cities, TJ showed the highest contamination level of PBDEs in the mollusks, similar to the case of HBCDs.

The $\sum_{12}$ PBDE levels in this work combined with those in our previous study ${ }^{18}$ illustrated the temporal trend in mollusks of the Chinese Bohai Sea, as shown in Figure 3. Concentrations

$\mathrm{BD}[1] 128=\mathrm{BDE} 47,66171 \square \mathrm{BD}[85 \cdot 991130 \quad \mathrm{BDE} 38 \cdot 1551154=\mathrm{BDE}-183$
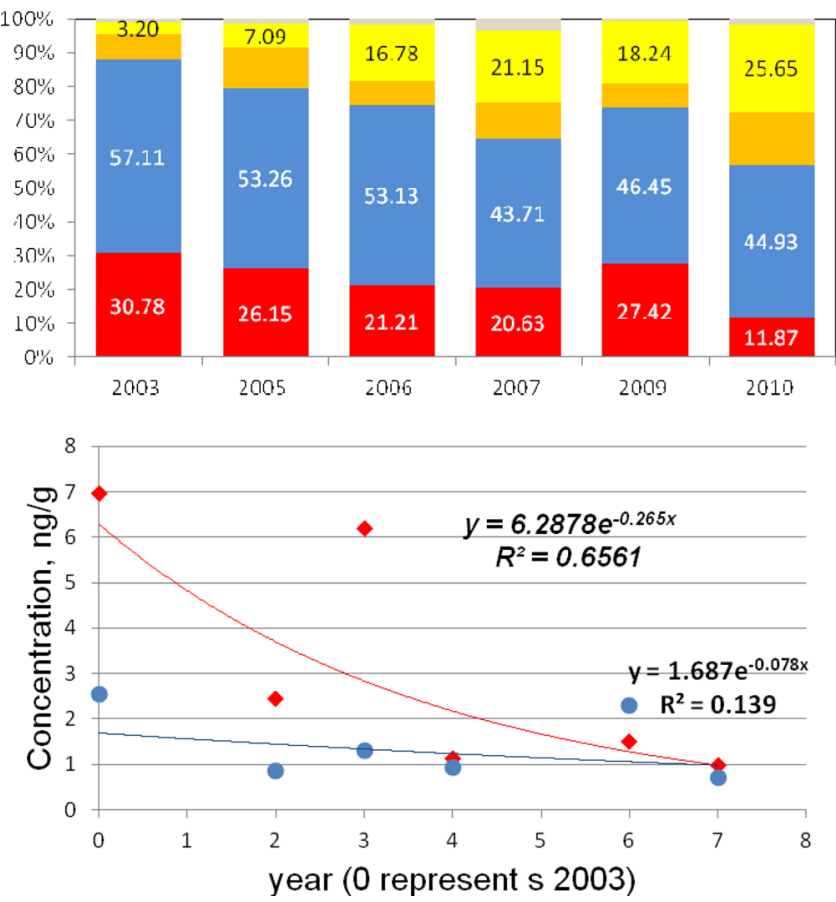

Figure 3. Temporal trends of PBDE profiles and concentrations. In the lower panel, the red dots show the mean whereas the blue dots represent the median values.

of $\sum_{12} \mathrm{PBDE}$ in mollusks decreased from $7.0 \mathrm{ng} / \mathrm{g} \mathrm{dw}$ (singular values are excluded) in 2003 to $1.0 \mathrm{ng} / \mathrm{g} \mathrm{dw}$ in 2010. During this time period, the half-life of $\sum_{12}$ PBDEs was $2.3 \pm 1.7$ years, which was calculated by applying, to the annual means, the firstorder kinetic function $C=C^{0} \mathrm{e}^{-k t}$, where $C$ is $\sum_{12} \mathrm{PBDE}$ at a given time $t ; C^{0}$ is the concentration of $\sum_{12} \mathrm{PBDE}$ in 2003, and the $k$ is the rate constant. This trend may be ascribed to the discontinued usage of penta-BDEs and octa-BDEs technical products on a global scale from 2004 and the restricted usage of PBDEs in China since 2006. Temporal trend studies from Europe, Asia, and the Arctic have also shown declining PBDE concentrations in aquatic organisms between the mid-1990s and the mid-2000s. ${ }^{6,25,33}$ On the other hand, congener pattern analysis in this study clearly indicated that the proportion of heavier PBDE congeners in the mollusks has increased gradually from 2003 to 2010 . The percentage of hexa-BDEs (the sum of BDEs 138, 153, and 154) in the $\sum_{12}$ PBDEs increased by 7 times between $2003(3.20 \%)$ and 2010 (25.7\%), while that of tri-BDEs (sum of BDEs 17 and 28) decreased by 61.4\% (Figure 3).

Bioindicator Selection. There are numerous recognized species of marine mollusks that are highly diverse in body size, composition, and structure. In our previous work, we have shown that Myt and Ost could be more suitable than other mollusks as bioindicators of contamination by OCPs, PCBs, and PBDEs in the Chinese Bohai Sea. ${ }^{18}$ In the present work, we further evaluated the possibility of these species as 
Component Plot in Rotated Space

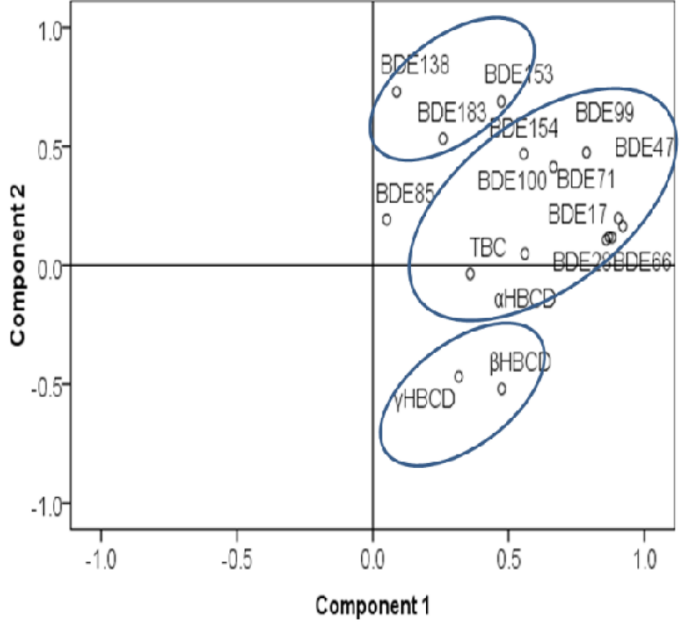

(a)

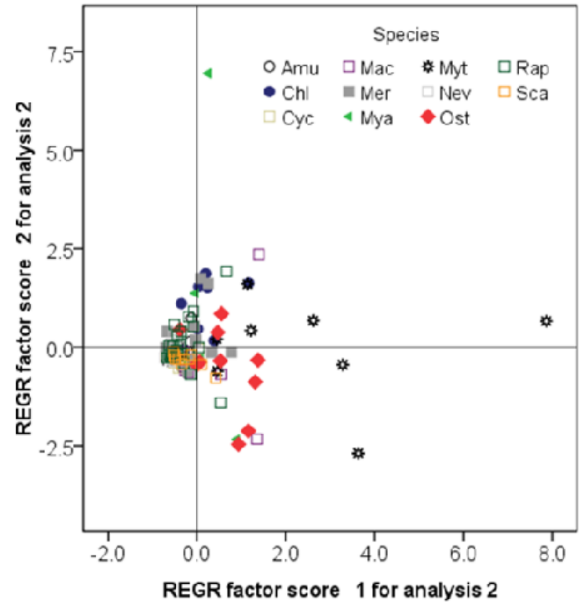

(b)

Figure 4. Loading (a) and score plots (b) of PCA by the database of BFRs (PBDEs, HBCDs, and TBC) in mollusks collected from the Chinese Bohai Sea in 2009 and 2010.
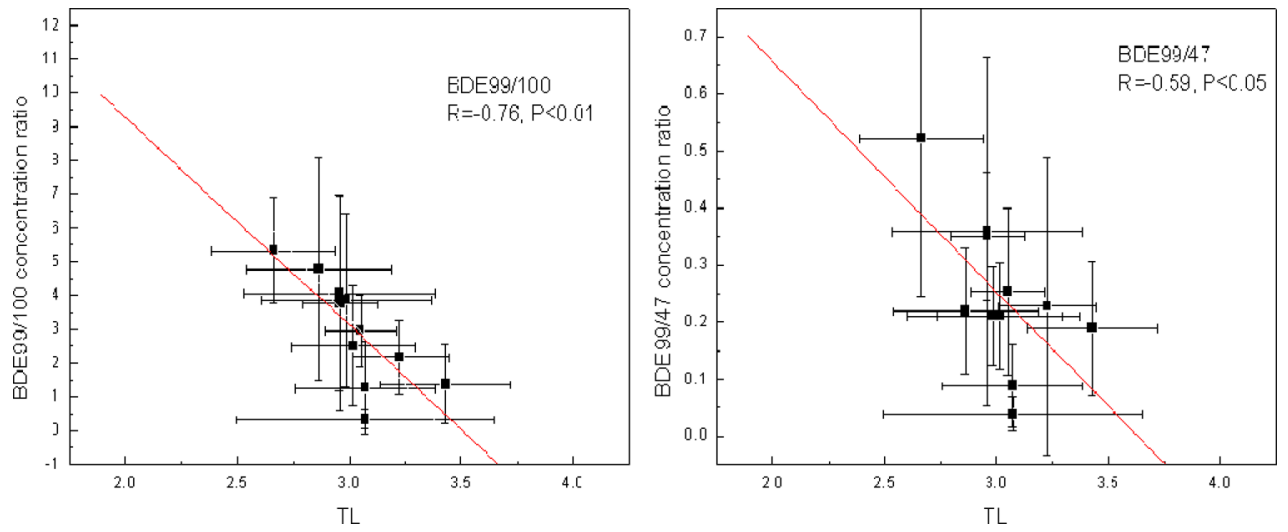

Figure 5. Relations between concentration radios of PBDEs congeners and TL in mollusks from the Bohai Sea.

bioindicators of contamination by TBC, HBCDs, and PBDEs in this area.

The linear correlation of concentrations (Figure S2, Supporting Information) and the similarity of calculated octanol-water partition coefficient $\left(K_{\text {ow }}\right)$ among penta-BDEs $\left(\log K_{\mathrm{ow}}=7.66\right)$, HBCDs $\left(\log K_{\mathrm{ow}}=7.74\right)$, and TBC $\left(\log K_{\mathrm{ow}}\right.$ $=7.37)^{7}$ suggested that the three BFRs may share similar mechanisms of bioaccumulation in aquatic organisms. Consequently, it is likely that Myt and Ost would also be more suitable in reflecting the extent of pollution by TBC and HBCDs in the Chinese Bohai Sea, since these two species seem to have higher bioaccumulative abilities than other selected mollusks. In order to test this hypothesis, principal component analysis (PCA) was applied to the measured concentration data. The results showed that the first two PCs represented $55.7 \%$ of the total variances of BFR concentrations in mollusks (Figure 4). Combined with the loading and score plots, TBC, the lower brominated PBDE congeners, and $\alpha$-HBCD were congregated into one group and more heavily accumulated in Myt than in other mollusks. Higher brominated PBDE congeners such as BDEs 153, 138, and 183 were located in upper $y$-axis (Figure 4a) and accumulated more in Chl and Myt, while $\gamma$-HBCD and $\beta$-HBCD were primarily accumulated in Myt and Ost. On the basis of the trends from the PCA plots, Myt was found to be the most sensitive and appropriate specie for indicating the contamination of TBC, PBDEs, and HBCDs in the Bohai Sea.

Trophic level (TL) of the biota is often used in studies on biomagnification in aquatic environment. In this work, TLs of the mollusks were estimated on the basis of their nitrogen isotope ratios $\left(\delta^{15} \mathrm{~N}\right){ }^{34}$ which ranged from 2.12 to 4.09 (Table 1). Among the 11 species, Sca had the widest range while Rap had the highest TL with a mean of 3.43 (Figure S4, Supporting Information, and Table 1), which were consistent with the findings from others studies. ${ }^{18,35}$ Results from multiple linear regression analysis (stepwise regression) showed the lipid content had stronger relationships with $\sum_{12}$ PBDEs and $\sum$ HBCDs than TL. No significant correlation was found between TBC concentration and lipid content $(R=-0.147, p>$ $0.05)$ or TL $(R=0.122, p>0.05)$ (Table S3, Supporting Information), although Ruan et al. ${ }^{7}$ indicated TBC was inclined to be enriched in the fat-rich organs of fish.

In order to explore the correlation of BFR concentrations and TL without the influence of lipid content, regression 
analysis was performed for the lipid-normalized concentrations of BFRs against TL (Figure S5, Supporting Information). Although the correlations were statistically insignificant $(p>$ $0.05)$, negative trends were observed for all the three BFRs, indicating potential trophic dilution rather than magnification in the portion of the marine food web involving mollusks. In the Bohai Sea, trophic dilutions have been previously reported for PAHs, PCDD/Fs, PCBs, HCHs, and PBDEs. ${ }^{18,36,37}$ However, some other POPs with comparable log $K_{\text {ow }}$ values, such as DDT, HCB, and coplanar PCBs, exhibited opposite trophodynamics in the same marine food web of the Bohai Sea, with their trophic magnification factor (TMF) values being all higher than $1 .^{37,38}$

$\log K_{\text {ow }}$ of the chemicals is not the only key factor governing the bioaccumulation potential. Their metabolic transformation rates, half-lives in organisms, and assimilation efficiencies may vary significantly and should also be taken into account. ${ }^{39}$ For example, the PBDE congener ratio BDE99/100 in most abiotic samples is approximately $80: 20$, which is comparable to the mean of 84:16 measured for industrial products Bromkal 70$5 \mathrm{DE}$, while the ratio is about 30:70 in biotic samples. ${ }^{40}$ In the present study, large differences in the ratio BDE99/100 were observed among mollusks species, with the lowest in Sca (25:75) and the highest in Mya (84:16). The strong negative dependence of this ratio on the TL $(R=-0.76, p<0.01)$, as shown in Figure 5, reveals the increase in bioaccumulation of BDE100 or biodegradation of BDE99 with the increasing TL among the mollusks. A similar negative correlation $(R=-0.59$, $p<0.05$ ) between the congener ratio BDE99/47 and the mollusks TL was obtained (Figure 5), indicating that mollusks species at higher TL in the food chain tend to be more capable of biotransforming BDE99 than BDE47. Future studies are warranted to investigate these phenomena.

In recent years, HBCDs have been proven to be globally ubiquitous. In the Persistent Organic Pollutants Review Committee meeting of 2011 (POPRC 7), HBCDs were considered for Annex F, implying that they could be recommended by POPRC to be listed under the Stockholm Convention in the foreseeable future. With the expected tightening of restrictions on HBCDs, their concentrations in the environment may start to decline. Correspondingly, due to the demand of the global market, the production and usages of novel flame retardants have started to increase. Accordingly, the detection of some new flame retardant chemicals in the environment have already been reported in the recent years. $^{41-45}$

\section{ASSOCIATED CONTENT}

\section{S Supporting Information}

Additional information as noted in the text. This material is available free of charge via the Internet at http://pubs.acs.org

\section{AUTHOR INFORMATION}

\section{Corresponding Author}

*Tel: 8610-6284-9334; fax: 8610-6284-9339; e-mail: ywwang@ rcees.ac.cn.

\section{Notes}

The authors declare no competing financial interest.

\section{ACKNOWLEDGMENTS}

This work was jointly supported by the National Basic Research Program of China (2009CB421605) and the National Natural
Science Foundation (20890111, 21007078, 21177149, 21177147).

\section{REFERENCES}

(1) A perspective on the development of brominate flame retardants in China: http://www.polymer.cn/Html/IndustryNews/2006-12/ 15/ 2007529102655763.htm.

(2) Shi, T.; Chen, S. J.; Luo, X. J.; Zhang, X. L.; Tang, C. M.; Luo, Y.; Ma, Y. J.; Wu, J. P.; Peng, X. Z.; Mai, B. X. Occurence of brominated flame retardants other than polybrominated dipehnyl ethers in environmental and biota samples from southern China. Chemosphere 2009, 74, 910-916.

(3) Hites, R. A. Polybrominated diphenyl ethers in the environment and in people: A meta-analysis of concentrations. Environ. Sci. Technol. 2004, 38, 945-956.

(4) UNEP, 2008. The Stockholm Convention on Persistent Organic Pollutants.

(5) Ueno, D.; Isobe, T.; Ramu, K.; Tanabe, S.; Alaee, M.; Marvin, C.; Inoue, K.; Someya, T.; Miyajima, T.; Kodama, H.; Nakata, H. Spatial distribution of hexabromocyclododecanes (HBCDs), polybrominated diphenyl ethers (PBDEs) and organochlorines in bivalves from Japanese coastal waters. Chemosphere 2010, 78, 1213-1219.

(6) Johansson, I.; Heas-Moisan, K.; Guiot, N.; Munschy, C.; Tronczynski, J. Polybrominated diphenyl ethers (PBDEs) in mussels from selected French coastal sites: 1981-2003. Chemosphere 2006, 64, 296-305.

(7) Ruan, T.; Wang, Y. W.; Wang, C.; Wang, P.; Fu, J. J.; Yin, Y. G.; Qu, G. B.; Wang, T.; Jiang, G. B. Identification and evaluation of a novel heterocyclic brominated flame retardant tris(2,3-dibromopropyl) isocyanurate in environmental matrices near a manufacturing plant in southern China. Environ. Sci. Technol. 2009, 43, 3080-3086.

(8) Flame-resistant styrene polymers. Inventor data not available; corporate source data not available (1959), GB 825611 19591216, Database: CAPLUS.

(9) Lv, J. P.; Yao, J. Y.; You, Y. R. Microencapsulated TBC and its application. China Plastics Ind. 1999, 27, 43-44.

(10) Howard, P. H.; Muir, D. C. G. Identifying new persistent and bioaccumulative organics among chemicals in commerce. Environ. Sci. Technol. 2010, 44, 2277-2285.

(11) Li, J.; Zhang, X.; Lu, J. Y.; Zhang, J.; Ruan, T.; Zhou, Q. F.; Jiang, G. B.; Liang, Y. Impaired gas bladder inflation in zebrafish exposed to a novel heterocyclic brominated flaome retardant tris(2,3dibromopropyl) isocyanurate. Environ. Sci. Technol. 2011, 45, In Press.

(12) Zhang, X.; Li, J.; Chen, M. J.; Wu, L.; Zhang, C.; Zhang, J.; Zhou, Q. F.; Liang, Y. Toxicity of the brominated flame retardant tris(2,3-dibromopropyl) isocyanurate in zebrafish (Danio rerio). Chin. Sci. Bull. 2011, 56, 1548-1555.

(13) Tanabe, S.; Subramanian, A. Bioindicators of POPs: Monitoring in Developing Countries; Kyoto University Press: Kyoto, Japan, 2006.

(14) Isobe, T.; Takada, H.; Kanai, M.; Tsutsumi, S.; Isobe, K. O.; Boonyatumanond, R; Zakaria, M. P. Distribution of polycyclic aromatic hydrocarbons (PAHs) and phenolic endocrine disrupting chemicals in south and southeast Asian mussels. Environ. Monitor. Assess. 2007, 135, 423-440.

(15) Xia, C.; Lam, J. C. W.; Wu, X.; Sun, L.; Xie, Z.; Lam, P. K. S., Hexabromocyclododecanes (HBCDs) in marine fishes along the Chinese coastline. Chemosphere 82, 1662-1668.

(16) Gao, S. T.; Wang, J. Z.; Yu, Z. Q.; Guo, Q. R.; Sheng, G. Y.; Fu, J. M. Hexabromocyclododecanes in surface soils from E-waste recycling areas and industrial areas in South China: Concentrations, diastereoisomer- and enantiomer-specific profiles, and inventory. Environ. Sci. Technol. 2011, 45, 2093-2099.

(17) Meng, X. Z.; Duan, Y. P.; Yang, C.; Pan, Z. Y.; Wen, Z. H.; Chen, L. Occurrence, sources, and inventory of hexabromocyclododecanes (HBCDs) in soils from Chongming Island, the Yangtze River Delta (YRD). Chemosphere 2011, 82, 725-731.

(18) Wang, Y. W.; Wang, T. H.; Li, A.; Fu, J. J.; Wang, P.; Zhang, Q H.; Jiang, G. B. Selection of bioindicators of polybrominated diphenyl ethers, polychlorinated biphenyls, and organochlorine pesticides in 
mollusks in the Chinese Bohai Sea. Environ. Sci. Technol. 2008, 42, 7159-7165.

(19) Wang, Y. W.; Zhang, Q. H.; Lv, J. X.; Li, A.; Liu, H. X.; Li, G. G.; Jiang, G. B. Polybrominated diphenyl ethers and organochlorine pesticides in sewage sludge of wastewater treatment plants in China. Chemosphere 2007, 68, 1683-1691.

(20) Feng, J. Y.; Wang, Y. W.; Ruan, T.; Qu, G. B.; Jiang, G. B. Simultaneous determination of hexabromocyclododecanes and tris (2,3-dibromopropyl) isocyanurate using LC-APCI-MS/MS. Talanta 2010, 82, 1929-1934.

(21) Estimation Programs Interface (EPI) Suite v4.10; U.S. Environmental Protection Agency, October 2011. http://www.epa.gov/oppt/ exposure/pubs/episuitedl.htm.

(22) Fernandes, A.; Dicks, P.; Mortimer, D.; Gem, M.; Smith, F.; Ield, M. D.; White, S.; Rose, M. Brominated and chlorinated dioxins, PCBs and brominated flame retardants in Scottish shellfish: Methodology, occurrence and human dietary exposure. Mol. Nutr. Food Res. 2008, 52, 238-249.

(23) Ramu, K.; Kajiwara, N.; Sudaryanto, A.; Isobe, T.; Takahashi, S.; Subramanian, A.; Ueno, D.; Zheng, G. J.; Lam, P. K. S.; Takada, H.; Zakaria, M. P.; Viet, P. H.; Prudente, M.; Tana, T. S.; Tanabe, S. Asian mussel watch program: Contamination status of polyhrominated diphenyl ethers and organochlorines in coastal waters of Asian countries. Environ. Sci. Technol. 2007, 41, 4580-4586.

(24) Xian, Q. M.; Ramu, K.; Isobe, T.; Sudaryanto, A.; Liu, X. H.; Gao, Z. S.; Takahashi, S.; Yu, H. X.; Tanabe, S. Levels and body distribution of polybrominated diphenyl ethers (PBDEs) and hexabromocyclododecanes (HBCDs) in freshwater fishes from the Yangtze River, China. Chemosphere 2008, 71, 268-276.

(25) Lam, J. C. W.; Lau, R. K. F.; Murphy, M. B.; Lam, P. K. S. Temporal trends of hexabromocyclododecanes (HBCDs) and polybrominated diphenyl ethers (PBDEs) and detection of two novel flame retardants in marine mammals from Hong Kong, South China. Environ. Sci. Technol. 2009, 43, 6944-6949.

(26) Gauthier, L. T.; Hebert, C. E.; Weseloh, D. V. C.; Letcher, R. J. Current-use flame retardants in the eggs of herring gulls (Larus argentatus) from the Laurentian Great lakes. Environ. Sci. Technol. 2007, 41, 4561-4567.

(27) Oros, D. R.; Hoover, D.; Rodigari, F.; Crane, D.; Sericano, J. Levels and distribution of polybrominated diphenyl ethers in water, surface sediments, and bivalves from the San Francisco Estuary. Environ. Sci. Technol. 2005, 39, 33-41.

(28) Moon, H. B.; Kannan, K.; Lee, S. J.; Choi, M. Polybrominated diphenyl ethers (PBDEs) in sediment and bivalves from Korean coastal waters. Chemosphere 2007, 66, 243-251.

(29) Liu, Y.; Zheng, G. J.; Yu, H. X.; Martin, M.; Richardson, B. J.; Lam, M. H. W.; Lam, P. K. S. Polybrominated diphenyl ethers (PBDEs) in sediments and mussel tissues from Hong Kong marine waters. Mar. Pollut. Bull. 2005, 50, 1173-1184.

(30) Bayen, S.; Thomas, G. O.; Lee, H. K.; Obbard, J. P. Occurrence of polychlorinated biphenyls and polybrominated diphenyl ethers in green mussels (Perna viridis) from Singapore, Southeast Asia. Environ. Toxicol. Chem. 2003, 22, 2432-2437.

(31) Wan, Y.; Hu, J. Y.; Zhang, K.; An, L. H. Trophodynamics of polybrominated diphenyl ethers in the marine food web of Bohai Bay, North China. Environ. Sci. Technol. 2008, 42, 1078-1083.

(32) Jin, J.; Wang, Y.; Liu, W. Z.; Tang, X. Y. Level and distribution of polybrominated diphenyl ethers in soil from Laizhou Bay. Acta Sci. Circumstantiae 2008, 28, 1463-1468.

(33) Vorkamp, K.; Riget, F. F.; Bossi, R.; Dietz, R. Temporal trends of hexabromocyclododecane, polybrominated diphenyl ethers and polychlorinated biphenyls in ringed seals from East Greenland. Environ. Sci. Technol. 2011, 45, 1243-1249.

(34) Wang, Y. W.; Li, X. M.; Li, A.; Wang, T.; Zhang, Q. H.; Wang, P.; Fu, J. J.; Jiang, G. B. Effect of municipal sewage treatment plant effluent on bioaccumulation of polychlorinated biphenyls and polybrominated diphenyl ethers in the recipient water. Environ. Sci. Technol. 2007, 41, 6026-6032.
(35) Wan, Y.; Hu, J. Y.; An, L. H.; An, W.; Yang, M.; Mitsuaki, I.; Tatsuya, H.; Tao, S. Determination of trophic relationships within a Bohai Bay food web using stable delta $\mathrm{N}-15$ and delta C-13 analysis. Chin. Sci. Bull. 2005, 50, 1021-1025.

(36) Wan, Y.; Jin, X.; Hu, J.; Jin, F. Trophic dilution of polycyclic aromatic hydrocarbons (PAHs) in a marine food web from Bohai Bay, North China. Environ. Sci. Technol. 2007, 41, 3109-3114.

(37) Wan, Y.; Hu, J. Y.; Yang, M.; An, L. H.; An, W.; Jin, X. H.; Hattori, T.; Itoh, M. Characterization of trophic transfer for polychlorinated dibenzo- $p$-dioxins, dibenzofurans, non- and monoortho polychlorinated biphenyls in the marine food web of Bohai Bay, north China. Environ. Sci. Technol. 2005, 39, 2417-2425.

(38) Hu, J. Y.; Jin, F.; Wan, Y.; Yang, M.; An, L. H.; An, W.; Tao, S. Trophodynamic behavior of 4-monylphenol and nonylphenol polyethoxylate in a marine aquatic food web from Bohai Bay, North China: Comparison to DDTs. Environ. Sci. Technol. 2005, 39, 48014807.

(39) Mackay, D.; Fraser, A. Bioaccumulation of persistent organic chemicals: Mechanisms and models. Environ. Pollut. 2000, 110, 375391.

(40) Christensen, J. H.; Glasius, M.; Pecseli, M.; Platz, J.; Pritzl, G. Polybrominated diphenyl ethers (PBDEs) in marine fish and blue mussels from southern Greenland. Chemosphere 2002, 47, 631-638.

(41) Sverko, E.; Tomy, G. T.; Reiner, E. J.; Li, Y. F.; MeCarry, B. E.; Arnot, J. A.; Law, R. J.; Hites, R. A. Dechlorane plus and related compounds in the environment: A review. Environ. Sci. Technol. 2011, $45,5088-5098$.

(42) Qu, G. B.; Shi, J. B.; Wang, T.; Fu, J. J.; Li, Z. N.; Wang, P.; Ruan, T.; Jiang, G. B. Identification of tetrabromobisphenol A diallyl ether as an emerging neurotoxicant in environmental sample by bioassay-directed fractionation and HPLC-AAPCI-MS/MS. Environ. Sci. Technol. 2011, 45, 5009-5016.

(43) Tomy, G. T.; Pleskach, K.; Arsenault, G.; Potter, D.; Mccrindle, R.; Marvin, C. H.; Sverko, E. D.; Tittlemier, S. Identification of the novel cycloaliphatic brominated flame retardant 1,2-dibromo-4-(1,2dibromoethyl) cyclohexane in Canadian Arctic beluga (Delphinapterus leucas). Environ. Sci. Technol. 2008, 42, 543-549.

(44) Yang, R. Q.; Wei, H.; Guo, J. H.; McLeod, C.; Li, A.; Sturchio, N. Historically and currently used dechloranes in the sediments of the Great Lakes. Environ. Sci. Technol. 2011, 45, 5156-5163.

(45) Yang, R. Q.; Wei, H.; Guo, J. H.; Li, A. Emerging brominated flame retardants in the sediment of the Great Lakes. Environ. Sci. Technol. 2012, 46 (6), 3119-3126. 